\title{
The IL-6 rs 12700386 polymorphism is associated with an increased risk of developing osteoarthritis in the knee in the Chinese Han population: a case-control study
}

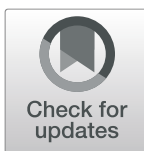

Hui Yang ${ }^{1}$, Xindie Zhou', Dongmei $X u^{1 *}$ and Gang Chen $^{2^{*}}$ (D)

\begin{abstract}
Background: This case-control study aims to examine the association between the Interleukin-6 (IL-6) rs12700386 polymorphism and the increased risk of developing osteoarthritis (OA) in the knee in the Chinese Han population.

Methods: We extracted DNA from 763 subjects (352 OA patients and 411 healthy controls). The relative expression levels of IL-6 in blood samples of patients with knee OA was determined by quantitative reverse transcription PCR (qRT-PCR) and polymerase chain reaction restriction fragment length polymorphism (PCR-RFLP) was used for genotyping the IL-6 gene polymorphism.

Results: We found that the IL-6 polymorphism rs12700386 enhanced patient susceptibility to developing knee OA. Based on a subgroup analysis, the risk of developing knee OA was elevated in smokers, drinkers, and subjects $\geq 55$ years old or with $\mathrm{BMI} \geq 25 \mathrm{~kg} / \mathrm{m}^{2}$. The combination of smoking, drinking, and having the rs 12700386 genotype led to an increase in the risk of developing knee $O A$, indicating that an underlying interaction between gene and environment exists. The rs 12700386 genotype was found to be correlated with an increase in IL-6 expression. We also found that IL-6 levels were significantly higher in the CC genotype compared to the GG genotype carriers in OA patients.
\end{abstract}

Conclusion: These data suggest that the rs 12700386 polymorphism in the IL- 6 gene leads to an increase in the risk of knee OA in Chinese Han individuals.

Keywords: IL-6, Osteoarthritis, Case-control study

\section{Background}

Osteoarthritis (OA) is representative joint disease associated with damage to the synovial joint structure and function [1] and worldwide is estimated to affect $10 \%$ of men and $18 \%$ of women who are 60 years and older [2]. Clinically, OA most frequently affects the knee joint [3]

\footnotetext{
* Correspondence: changzhouxdm@163.com; chengangjxey@126.com 'Department of Orthopedics, The Affiliated Changzhou No.2 People's Hospital of Nanjing Medical University, Changzhou 213000, China ${ }^{2}$ Department of Orthopedic Surgery, The Second Affiliated Hospital of Jiaxing University, Jiaxing 314000, China
}

and its occurrence is influenced by obesity, smoking, joint damage, heredity, and inflammation [4]. It is a multifactorial disease with an important genetic component [5]. In the last decade, genome-wide association studies have discovered many new genetic risk factors for OA [5].

IL-6 is a four-helix cytokine containing 184 amino acids, secreted by many cell types in response to infection, cancer, and inflammation [6]. It can effectively regulate $\mathrm{B}$ and $\mathrm{T}$ cell responses and coordinate activities of both the innate and adaptive immune systems [7]. IL-

(c) The Author(s). 2020 Open Access This article is licensed under a Creative Commons Attribution 4.0 International License, which permits use, sharing, adaptation, distribution and reproduction in any medium or format, as long as you give appropriate credit to the original author(s) and the source, provide a link to the Creative Commons licence, and indicate if changes were made. The images or other third party material in this article are included in the article's Creative Commons licence, unless indicated otherwise in a credit line to the material. If material is not included in the article's Creative Commons licence and your intended use is not permitted by statutory regulation or exceeds the permitted use, you will need to obtain permission directly from the copyright holder. To view a copy of this licence, visit http://creativecommons.org/licenses/by/4.0/ The Creative Commons Public Domain Dedication waiver (http://creativecommons.org/publicdomain/zero/1.0/) applies to the data made available in this article, unless otherwise stated in a credit line to the data. 
6 is an important regulator of bone homeostasis which can trigger osteoclast differentiation and bone resorption [8]. Goldring et al. found that IL-6 production underwent an up-regulation by IL- $1 \beta$ together with matrix metalloproteinase, and that an increase in IL-6 suppressed collagen-2 production, leading to joint damage [9], while Sakao K et al. showed that there was a positive correlation between increased IL- 6 expression and OA radiographic progression [10]. We therefore propose that IL-6 is a pivotal candidate gene for OA susceptibility.

Polymorphisms in the IL-6 gene, located at 7p21-24, are associated with an increased risk of OA. Singh et al. showed that there was a significant association with IL-6 rs1800795 and rs1800796 and an increased risk of OA [11] and Lv et al found that IL-6 -634G/C was associated increased susceptibility to end-stage knee OA [12]. The IL-6 rs12700386 polymorphism, located in the promoter region of $7 \mathrm{p} 22$ where guanine $(\mathrm{G})$ is replaced with cytosine $(C)$ in the -2954 position, may affect the risk of OA by activating gene expression and increasing serum IL-6 levels. The minor allele $(C)$ frequency in the population was 0.133, published in the Ensembl database. The impact of the IL-6 rs12700386 polymorphism on OA risk has never been explored in the Chinese Han population. This paper presents a case-control study of 352 OA patients and 411 healthy controls, which aimed to investigate whether the rs12700386 polymorphism is related to knee OA risk and IL-6 gene levels in the Chinese Han population.

\section{Methods}

\section{Subjects}

Three hundred fifty-two OA patients and 411 healthy controls were recruited from the Affiliated Changzhou No.2 People's Hospital of Nanjing Medical University and the Second Affiliated Hospital of Jiaxing University. All were ethnic Han Chinese who were not genetically related to each other. The Kellgren Lawrence scoring (K-L scoring) system was used to radiologically diagnose each patient, the functional Lequesne index was used to assess each subject's functional or symptomatic status, and the Visual Analog Scale (VAS) was used to evaluate pain. There were three inclusion criteria for the OA patient group. Patients must have 1) Symptoms and/or signs of knee OA, 2) Radio-graphic abnormality with a $\mathrm{K}-\mathrm{L}$ grade $\geq 2$, and 3) No other form of arthritis. Demographic characteristics [gender, age, smoking, alcohol consumption, and body mass index (BMI)] and clinical characteristics of disease severity [Lequesne function index, visual analog scale (VAS), erythrocyte sedimentation rate (ESR), and C-reactive protein (CRP)] were obtained from medical records. Healthy controls were selected from patients in orthopedics clinics and general surgery in one hospital while collecting samples. The exclusion criteria for the control group were; 1) History of knee or hip replacement, 2) Application of corticosteroids or bi-immunosuppressors, 3) Parkinson's disease, or 4) Sequelae of stroke. Table 1 lists the characteristics of all the subjects. Informed consent was obtained from all the subjects, and the study received approval from the Ethics Committee of the hospital. The study was performed according to the tenets of the Helsinki Declaration. All participating patients and institutions allowed us to access the data used in this study.

\section{Blood sampling and genotyping}

A TIANamp blood DNA kit (Tiangen Biotech, Beijing, China) was used according to manufacturer's instructions to extract patient blood samples and isolate genomic DNA from leukocytes. IL-6 concentration in the serum of $351 \mathrm{OA}$ patients and 351 matched healthy controls was determined using an enzyme-linked immunosorbent assay Kit (Boster, Wuhan, China). Extracted samples were stored at $-20^{\circ} \mathrm{C}$ until further use. The IL-6 rs12700386 polymorphism was characterized by a polymerase chain reaction restriction fragment

Table 1 The general characteristics of study participants

\begin{tabular}{|c|c|c|c|}
\hline Variable & Cases $(n=352)$ & Controls $(n=411)$ & $P$ \\
\hline Age (years) & $61.39 \pm 10.42$ & $61.03 \pm 9.89$ & 0.629 \\
\hline Sex & & & 0.884 \\
\hline Male & $166(47.2 \%)$ & $191(46.5 \%)$ & \\
\hline Female & $186(52.8 \%)$ & $220(53.5 \%)$ & \\
\hline Smoking & & & 0.695 \\
\hline Yes & $111(31.5 \%)$ & $124(30.2 \%)$ & \\
\hline No & $241(68.5 \%)$ & $287(69.8 \%)$ & \\
\hline Alcohol & & & 0.762 \\
\hline Yes & $124(35.2 \%)$ & $150(36.5 \%)$ & \\
\hline NO & $228(64.8 \%)$ & $261(63.5 \%)$ & \\
\hline BMI $\left(\mathrm{kg} / \mathrm{m}^{2}\right)$ & $24.61 \pm 1.31$ & $24.58 \pm 1.49$ & 0.814 \\
\hline \multicolumn{4}{|l|}{ Affected leg } \\
\hline Left & $215(61.1 \%)$ & & \\
\hline Right & $137(38.9 \%)$ & & \\
\hline ESR $(\mathrm{mm} / \mathrm{h})$ & $18.47 \pm 9.64$ & - & \\
\hline CRP (mg/L) & $19.77 \pm 14.42$ & - & \\
\hline VAS & $5.66 \pm 1.59$ & - & \\
\hline Lequesnes' index & $14.50 \pm 2.06$ & & \\
\hline \multicolumn{4}{|c|}{ kellgren-Lawrence grade } \\
\hline$\|$ & $152(43.2 \%)$ & & \\
\hline III & $143(40.6 \%)$ & & \\
\hline IV & $57(16.2 \%)$ & & \\
\hline
\end{tabular}

$B M I$ body mass index, ESR erythrocyte sedimentation rate, CRP C-Reactive protein, VAS visual Analogue Scale 
length polymorphism (PCR-RFLP) with the following sequence-specific primers: 5'-GCGACAGGCCTCTC CAG TCT-3' (forward) and 5'-GCAGTCACACCGGC TAGGTC' (reverse). 5\% of samples were randomly selected to receive repeated assays, and we found that the accuracy rate was $100 \%$.

\section{Quantitative real-time polymerase chain reaction (qRT- PCR)}

Trizol (Invitrogen, Carlsbad, USA) was used to isolate total RNA from the peripheral venous blood, and the oligo primer and SuperscriptII (Invitrogen) were used to reverse-transcribe the RNA to obtain cDNA. The relative gene expression of IL- 6 was quantified using the Taqman method with beta-actin used as an internal reference. The forward and reverse primers for PCR used were: 5'-GAG CTTCAGGCAGGCAGTATC-3' (forward) and 5'-GTATAG ATT CTT TCCTTTGAG GC3' (reverse); (IL-6); 5' -ACCACCATG GAGAAGGCT GG-3' (forward) and 5'-CTC AGTGTAGCCCAGGAT GC-3'(reverse)' ( $\beta$-actin). Relative expression levels were analyzed using the $2-\Delta \Delta$ CT method.

\section{Statistical analyses}

All statistical analyses were performed using SPSS 22.0 (SPSS Inc., USA) and statistical graphs were made with GraphPad Prism 5 (GraphPad Software, La Jolla, CA). A student's t-test or $\chi^{2}$ test was used to assess the differences between patients and controls in the mean and frequency distribution of clinical and demographic characteristics. Observed number of genotypes was compared with a Chi-square $(\chi 2)$ analysis, with the assumption that the population was in a Hardy-Weinberg equilibrium (HWE). An independent sample t-test or a one-way ANOVA was used to test the normal distribution of continuous variables, with results shown as mean \pm standard deviation. We analyzed allele and genotype distributions between patients and the controls, and conducted stratified analyses according to alcohol consumption, smoking, sex, and age of subject. The odds ratio (OR) and $95 \%$ confidence interval $(\mathrm{CI})$ were calculated in a logistic regression to assess the correlation between the IL- 6 gene polymorphism and risk of OA. A cross-over analysis was used to assess the effects of the interactions between environmental factors, such as smoking and/or drinking, and genetic factors on the risk of OA. $P<0.05$ implied a significant level of association. The association between the IL-6 rs12700386 polymorphism and IL-6 serum levels was evaluated using the Mann-Whitney $U$ test.

\section{Power analysis}

The comprehensive statistical power of our study design was analyzed using Genetic Power Calculator 33 with a significance value of 0.05 .

\section{Results}

Characteristics of subjects in study

Detailed information of all individuals in study is shown in Table 1. The average ages of the patient and control groups were 61.39 and 61.03 years old, respectively and mean BMIs were 24.61 and $24.58 \mathrm{~kg} / \mathrm{m}^{2}$, respectively. There were no significant differences between the groups in regard to age, BMI, or sex, and the distributions of smokers and drinkers were equal group. Table 1 lists the relevant indexes, including affected leg, CRP, ESR, VAS, Lequensene's index, and the K-L grade.

\section{Relationship between the IL- 6 rs12700386 polymorphism and $\mathrm{OA}$ risk}

The allele and genotype distribution of IL-6 rs12700386 polymorphism is shown in Table 2. The HWE test found that there was no obvious deviation in genotypic frequency among the controls, indicating that the subjects in this study are representative of the local population. The IL-6 rs12700386 polymorphism led to an obvious increase in the risk of OA risk in dominant, homozygous, and allelic models. A logistic regression analyses showed that the $\mathrm{CC}$ genotype significantly increased the risk of OA (CC vs. GG: OR and 95\% CI, 2.01 (1.04, 3.89), $P=0.045$ ). (Table 2). Analysis of the allelic model revealed that the $C$ allele was associated with a higher risk of OA (C vs. G: $1.38(1.08,1.75), P=0.010)$ (Table $2)$. This significant association was also observed in the dominant models. Stratified analyses of age, smoking, drinking status, and BMI revealed that there was a significantly higher risk of OA in drinkers, smokers, those over 55 years old, and with a BMI above $25 \mathrm{~kg} / \mathrm{m}^{2}$. (Table 3). The rs12700386 polymorphism however, did not affect the risk of $\mathrm{OA}$ in regard to the abovementioned indexes (Table 4).

Based on the RT-PCR analysis, higher IL-6 expression was seen in the CC genotype compared to the GG genotype $(P<0.001)$ (Fig. 1$)$.

\section{Association between IL- 6 rs12700386 polymorphism and serum IL-6 levels}

Data indicated that the average IL-6 serum levels were significantly higher in $\mathrm{OA}$ patients $(\mathrm{P}<0.001$, Supplemental Figure $1 \mathrm{a}$ ) and that genotype $\mathrm{CC}$ patients had higher IL-6 serum levels compared to genotype GG patients $(P<0.05$, Supplemental Figure $1 \mathrm{~b})$. However, this polymorphism was not associated with alteration in IL-6 serum levels in the control subjects (Supplemental Figure $1 \mathrm{c}$ ).

\section{Cross-over analysis}

The OR and 95\% CI specific to two combining exposure models (IL-6 gene variants and smoking or drinking) were calculated (Table 5). With regards to the 
Table 2 The association of genotype and allele of IL-6 rs12700386 polymorphism with osteoarthritis risk

\begin{tabular}{|c|c|c|c|c|c|}
\hline \multirow[t]{2}{*}{ Genotype } & \multirow{2}{*}{$\begin{array}{l}\text { Genotypes } \\
\text { and alleles }\end{array}$} & \multicolumn{2}{|c|}{ Frequencies $N(\%)$} & \multirow[t]{2}{*}{ OR $(95 \% \mathrm{Cl})$} & \multirow[t]{2}{*}{$P$} \\
\hline & & Cases $(n=351)$ & Controls $(n=409)$ & & \\
\hline \multicolumn{6}{|l|}{ rs12700386 } \\
\hline Co-dominant & GG & $193(55.0 \%)$ & $259(63.3 \%)$ & 1.00(reference) & \\
\hline Heterozygote & GC & $134(38.2 \%)$ & $134(32.8 \%)$ & $1.34(0.99,1.82)$ & 0.063 \\
\hline Homozygote & $\mathrm{CC}$ & $24(6.8 \%)$ & $16(3.9 \%)$ & $2.01(1.04-3.89)$ & 0.045 \\
\hline \multirow[t]{2}{*}{ Dominant } & GG & $193(55.0 \%)$ & $259(63.3 \%)$ & 1.00(reference) & \\
\hline & $\mathrm{GC}+\mathrm{CC}$ & $158(45.0 \%)$ & $150(36.7 \%)$ & $1.41(1.06-1.89)$ & 0.022 \\
\hline \multirow[t]{2}{*}{ Recessive } & $\mathrm{GC}+\mathrm{GG}$ & $327(93.2 \%)$ & $393(96.1 \%)$ & 1.00(reference) & \\
\hline & CC & $24(6.8 \%)$ & $16(3.9 \%)$ & $1.80(0.94-3.45)$ & 0.075 \\
\hline \multirow[t]{2}{*}{ Allele } & G & $520(74.1 \%)$ & $652(79.7 \%)$ & 1.00(reference) & \\
\hline & C & $182(25.9 \%)$ & $166(20.3 \%)$ & $1.38(1.08-1.75)$ & 0.010 \\
\hline
\end{tabular}

The genotyping was successful in 351 cases and 409 controls for rs12700386; Bold values are statistically significant $(P<0.05)$

rs12700386 polymorphism, the GG genotype had a more obvious effect on the risk of OA than the CC genotype. While smoking was shown to have no impact on the risk of $\mathrm{OA}$, smokers carrying the $\mathrm{CC}$ genotype were more likely to suffer from OA compared to non-smokers carrying the GG genotype $(\mathrm{OR}, 2.86,95 \% \mathrm{CI}, 1.25-6.56 ; P=$ $0.015)$. This indicated that there may be an interaction between the CC genotype and smoking. No interaction was seen between the GC genotype and smoking in terms of OA risk. A combined effect on OA risk was seen with the CC genotype of rs12700386 polymorphism and drinking, suggesting that there was an interaction between the CC genotype and drinking. There was no interaction between the GC genotype and drinking in terms of OA risk.

\section{Discussion}

In this study, we found that the IL-6 rs12700386 polymorphism led to an increased risk of OA, especially among drinkers, smokers, those older than 55 years old, and with a BMI $\geq 25 \mathrm{~kg} / \mathrm{m}^{2}$. The interactions between the IL-6 rs12700386 polymorphism and smoking and/or

Table 3 Stratified analyses between rs12700386 polymorphism and the risk of osteoarthritis

\begin{tabular}{|c|c|c|c|c|c|c|c|}
\hline \multirow[t]{2}{*}{ Variable } & \multicolumn{3}{|c|}{ (case/control) } & \multirow[b]{2}{*}{ GC vs. GG } & \multirow[b]{2}{*}{ CC vs. GG } & \multirow[b]{2}{*}{ CC vs. GC + GG } & \multirow[b]{2}{*}{ CC + GC vs. GG } \\
\hline & GG & GC & $\mathrm{CC}$ & & & & \\
\hline \multicolumn{8}{|l|}{ Sex } \\
\hline Male & 100/131 & $54 / 50$ & $11 / 8$ & $1.42(0.89-2.25) ; 0.156$ & $1.80(0.70-4.64) ; 0.238$ & $1.62(0.63-4.12) ; 0.351$ & $1.47(0.95-2.28) ; 0.094$ \\
\hline Female & $93 / 128$ & $80 / 84$ & $13 / 8$ & $1.31(0.87-1.97) ; 0.214$ & $2.24(0.89-5.61) ; 0.107$ & $1.99(0.81-4.91) ; 0.176$ & 1.39 (0.94-2.06); 0.110 \\
\hline \multicolumn{8}{|l|}{ Smoking } \\
\hline Yes & $78 / 103$ & $13 / 12$ & $19 / 9$ & $1.29(0.57-2.94) ; 0.674$ & 2.51 (1.09-5.78); 0.029 & 2.67 (1.15-6.18); 0.025 & $2.01(1.08-3.76) ; 0.029$ \\
\hline No & 115/156 & $121 / 122$ & $5 / 7$ & $1.35(0.95-1.91) ; 0.111$ & $0.97(0.30-3.13) ; 0.602$ & $0.84(0.26-2.69) ; 0.504$ & $1.33(0.94-1.87) ; 0.116$ \\
\hline & & & & & Alcohol & & \\
\hline Yes & $71 / 96$ & $39 / 46$ & $13 / 6$ & $1.15(0.68-1.94) ; 0.687$ & $2.93(1.06-8.08) ; 0.049$ & $2.80(1.03-7.59) ; 0.054$ & $1.35(0.83-2.21) ; 0.259$ \\
\hline No & $122 / 163$ & $95 / 88$ & $11 / 10$ & 1.44 (0.99-2.09); 0.058 & $1.47(0.61-3.57) ; 0.495$ & $1.25(0.89-1.76) ; 0.222$ & $1.45(1.00-2.07) ; 0.053$ \\
\hline \multicolumn{8}{|l|}{ Age (years) } \\
\hline$<55$ & $30 / 41$ & $48 / 60$ & $8 / 5$ & 1.09 (0.60-2.00); 0.878 & $2.19(0.65-7.35) ; 0.236$ & $2.07(0.65-6.58) ; 0.254$ & $1.18(0.65-2.13) ; 0.653$ \\
\hline$\geq 55$ & $163 / 218$ & $86 / 74$ & $16 / 11$ & 1.55 (1.07-2.25); 0.023 & $1.95(0.88-4.30) ; 0.110$ & $1.71(0.78-3.74) ; 0.235$ & 1.61 (1.13-2.28); 0.009 \\
\hline \multicolumn{8}{|c|}{$\operatorname{BMI}\left(\left(\mathrm{kg} / \mathrm{m}^{2}\right)\right.$} \\
\hline$<25$ & $96 / 111$ & $62 / 74$ & $9 / 7$ & $1.38(0.89-2.13) ; 0.153$ & $1.49(0.53-4.14) ; 0.605$ & $1.51(0.55-4.13) ; 0.453$ & $1.01(0.67-1.54) ; 0.518$ \\
\hline$\geq 25$ & $97 / 148$ & $72 / 60$ & $15 / 9$ & $1.83(1.19-2.81) ; 0.007$ & $2.54(1.07-6.04) ; 0.049$ & $2.05(0.88-4.80) ; 0.138$ & $1.92(1.28-2.89) ; 0.002$ \\
\hline
\end{tabular}

Bold values are statistically significant $(P<0.05)$ 
Table 4 Comparison of studied according to IL-6 genotypes in all osteoarthritis cases

\begin{tabular}{|c|c|c|c|c|c|c|c|c|c|}
\hline \multicolumn{10}{|l|}{$\overline{\mathrm{OA}}(n=351)$} \\
\hline IL-6 rs12700386 & & $\mathrm{GG}(n=193)$ & $\mathrm{GC}(n=134)$ & $\mathrm{CC}(n=24)$ & $P$ & $\mathrm{GC}+\mathrm{CC}(n=158)$ & $P$ & $\mathrm{GG}+\mathrm{GC}(n=327)$ & $P$ \\
\hline $\mathrm{ESR}, \mathrm{mm} / \mathrm{h}$ & Mean \pm SD & $18.14 \pm 10.61$ & $18.82 \pm 8.40$ & $19.29 \pm 8.33$ & 0.065 & $18.89 \pm 8.37$ & 0.468 & $18.42 \pm 9.76$ & 0.558 \\
\hline$C R P, m g / L$ & Mean \pm SD & $20.29 \pm 14.16$ & $19.49 \pm 15.06$ & $17.96 \pm 14.41$ & 0.509 & $19.25 \pm 14.74$ & 0.505 & $19.96 \pm 14.52$ & 0.477 \\
\hline VAS & Mean \pm SD & $5.64 \pm 1.51$ & $5.75 \pm 1.57$ & $5.50 \pm 2.06$ & 0.262 & $5.71 \pm 1.65$ & 0.698 & $5.69 \pm 1.54$ & 0.671 \\
\hline Lequesnes' index & Mean \pm SD & $14.38 \pm 2.04$ & $14.70 \pm 2.12$ & $14.46 \pm 1.79$ & 0.539 & $14.66 \pm 2.07$ & 0.204 & $14.51 \pm 2.08$ & 0.144 \\
\hline Affected leg & Left/right, $n$ & $117 / 76$ & $81 / 53$ & $16 / 8$ & 0.838 & $97 / 61$ & 0.913 & 198/129 & 0.667 \\
\hline $\mathrm{KL}$ grading & $\|I+\mid V /\|, n$ & $107 / 86$ & $82 / 52$ & $11 / 13$ & 0.305 & $93 / 65$ & 0.588 & 190/138 & 0.288 \\
\hline
\end{tabular}

SD Standard Deviation; Bold values are statistically significant $(P<0.05)$

drinking combined to lead to a further increase in risk for knee OA. Certain genotypes of the rs12700386 polymorphism were associated with increased IL-6 expression. We found that IL-6 levels were significantly higher in OA patients with the $\mathrm{CC}$ genotype compared to the GG genotype. However, the impact of rs12700386 on OA patients with regards to their clinical parameters remains unknown.

$\mathrm{OA}$ is characterized by the destruction of cartilage, remodeling of subchondral bone, and synovial membrane inflammation, all of which actively affect disease progression [13]. As shown in previous studies, tibiofemoral cartilage injury progression can be affected by reactive or inflammatory synovium [14]. Proinflammatory cytokines such as IL-6 and TNF, can dramatically mediate metabolic disorders as well as enhance catabolism of OA

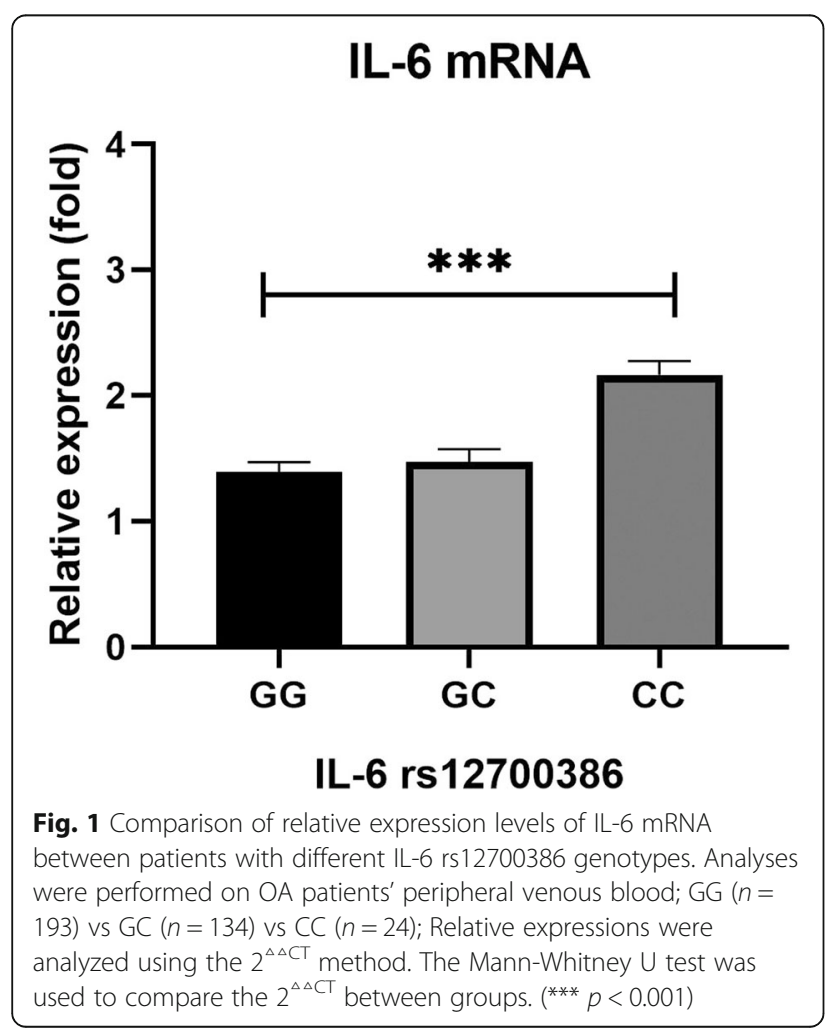

joint tissue [13]. The synovial fluid and serum of OA patients has been shown to have significantly increased IL6 levels [15]. A clinical trial involving OA patients showed that the risk of cartilage loss increases when IL6 and CRP have high baseline levels [16]. Increase in circulating IL-6 level and high BMI could lead to radiographic keen risk of OA [17]. In mice, IL-6 deficiency has been found to lead to a reduction in both the number of arthritic cells in the knee and the collageninduced arthritis response [18]. However, the exact mechanism of how IL-6 affects OA is of considerable debate.

IL-6 gene polymorphisms may change gene function and expression and regulate susceptibility to osteoarthritis $[11,12]$. We carried out this case-control study to explore the influence of IL-6 gene polymorphism on the risk of knee OA. Although Singh et al. found that there was no association between IL-6 rs12700386 and OA risk, they showed that IL- 6 plasma levels were significantly related to specific rs12700386 genotypes [11]. However, our findings showed that rs12700386 increased susceptibility to OA. This inconsistency between studies may be attributed to 4 main factors. First, people living in different environments have different diets and lifestyles. Second, our data indicated that there is between interplay between IL-6 gene rs12700386 polymorphism and some exposure factors. Third, different genotyping approaches, as well as inclusion criteria, were used in each study. Finally, OA exhibits clinical heterogeneity which can lead to the variation of OA classification between studies.

Based on stratified analyses, smokers, drinkers, subjects older than 55 , and with a BMI $\geq 25 \mathrm{~kg} / \mathrm{m}^{2}$ had an increased risk of knee OA. The cross-over analysis was thus used to estimate the combined effects of IL-6 gene polymorphism and smoking and drinking on knee OA risk. Data indicated that smokers carrying the GG genotype and drinkers carrying the GA genotype were more prone to OA. This also suggests that gene-environment interactions could influence the occurrence of OA. The combined effects of rs12700386 polymorphisms and smoking and/or drinking enhanced susceptibility to OA. 
Table 5 Genetic $(\mathrm{G})$ and environmental (E) factors $2 * 4$ fork analysis

\begin{tabular}{|c|c|c|c|c|c|}
\hline $\mathrm{G}^{\mathrm{a}}$ & $E^{b}$ & Case & Control & OR $(95 \% \mathrm{Cl}) ; P$ value & Reflecting information \\
\hline \multicolumn{6}{|l|}{ rs12700386 } \\
\hline CC vs. GG & Smoking & & & & \\
\hline+ & + & 19 & 9 & $2.86(1.25,6.56) ; 0.015$ & G, E combined effect \\
\hline+ & - & 5 & 7 & $0.97(0.30,3.13) ; 0.602$ & $G$ alone effect \\
\hline- & + & 78 & 103 & $1.03(0.70,1.50) ; 0.923$ & E alone effect \\
\hline- & - & 115 & 156 & 1.00 (reference) & Common control \\
\hline GC vs. GG & Smoking & & & & \\
\hline+ & + & 13 & 12 & $1.47(0.65,3.34) ; 0.402$ & G, E combined effect \\
\hline+ & - & 121 & 122 & $1.35(0.95,1.91) ; 0.111$ & $\mathrm{G}$ alone effect \\
\hline- & + & 78 & 103 & $1.03(0.70,1.50) ; 0.923$ & E alone effect \\
\hline- & - & 115 & 156 & 1.00 (reference) & Common control \\
\hline CC vs. GG & Drinking & & & & \\
\hline+ & + & 13 & 6 & $2.90(1.07,7.83) ; 0.034$ & G, E combined effect \\
\hline+ & - & 11 & 10 & $1.47(0.61,3.57) ; 0.495$ & $\mathrm{G}$ alone effect \\
\hline- & + & 71 & 96 & $0.99(0.67,1.45) ; 1.000$ & E alone effect \\
\hline- & - & 122 & 163 & 1.00 (reference) & Common control \\
\hline GC vs. GG & Drinking & & & & \\
\hline+ & + & 39 & 46 & $1.13(0.70,1.84) ; 0.620$ & G, E combined effect \\
\hline+ & - & 95 & 88 & $1.44(0.99,2.09) ; 0.058$ & $\mathrm{G}$ alone effect \\
\hline- & + & 71 & 96 & $0.99(0.67,1.45) ; 1.000$ & E alone effect \\
\hline- & - & 122 & 163 & 1.00 (reference) & Common control \\
\hline
\end{tabular}

${ }^{a} \mathrm{G}(+)$ : IL-6 gene rs12700386 variants (Heterozygous or homozygous); G (-): wild type

${ }^{b} \mathrm{E}(+)$ : smoking/non-smoking; $\mathrm{E}(-)$ : non-smoking/non-drinking

We also evaluated the associations between IL-6 gene polymorphisms and clinical characteristics of OA, however, no evidence of an association between rs12700386 and the clinical parameters of OA patients was found. To explore underlying mechanisms, qRT-PCR analysis showed that rs12700386 contributed to an increase IL-6 gene levels. We also found that IL-6 levels were significantly higher in CC genotype compared to GG genotype carriers in OA patients. Singh et al. demonstrated that genotypes of IL-6 rs12700386 was associated with increased levels of IL-6 in OA patients which was consistent with our study [11]. The possible mechanism for this may be that the change of guanine (G) to cytosine (C) at - 2954 position (-2954G/C; rs12700386) positively activate IL-6 transcriptional efficacy and hence, increases the IL-6 serum levels. Our study has shown that the IL6 gene polymorphism can affect IL- 6 gene expression and serum levels leading to an increase in the risk of knee OA.

This study does have some shortcomings. 1) only a moderate sample size was used, incapable of completely exploring how IL-6 gene rs12700386 polymorphism affected the knee OA susceptibility. 2) there may also have been some selection bias related to the ethnic groups as the participants were limited to the Chinese population.
3) only 1 polymorphism of the IL-6 gene was examined; it could not completely cover the gene. Further studies with haplotype analysis for IL-6 promoter polymorphisms are needed to profound our study. 4) relevant experiments were not carried out to fully elucidate underlying mechanisms. In further study, relevant experiments, such as transfection experiments, are need to demonstrate increased IL-6 promoter activity in the presence of the minor allele.

\section{Conclusions}

The rs12700386 polymorphism is associated with increased levels of IL- 6 gene expression and increased risk of knee OA in the Chinese Han population. These findings will be further verified in future studies utilizing a larger sample size.

\section{Supplementary information}

Supplementary information accompanies this paper at https://doi.org/10. 1186/s12881-020-01139-2.

Additional file 1: Figure S1. (a) The IL-6 serum levels of OA patients and matched heathy controls; (b) Association between IL-6 rs12700386 polymorphism and IL-6 serum levels in OA patients; (c) Association between IL-6 rs12700386 polymorphism and IL-6 serum levels in healthy controls. 


\section{Abbreviations}

IL-6: Interleukin-6; OA: Osteoarthritis; SNP: Single nucleotide polymorphism; PCR-RFLP: Polymerase chain reaction restriction fragment length polymorphism

\section{Acknowledgments}

Not Applicable,

\section{Authors' contributions}

DMX and GC took charge of conceiving as well as designing experiments. HY and XDZ carried out experiments. HY was responsible for data analysis. The paper was written by HY and revised by DMX. The paper had been reviewed by all authors, and gained their agreement with regard to paper content.

\section{Funding}

The research in the paper did not receive external funding.

\section{Availability of data and materials}

The datasets used and/or analyzed during the current study are available from the corresponding author on reasonable request.

\section{Ethics approval and consent to participate}

All procedures of the study were in accordance with the principles of the Declaration of Helsinki and were approved by the clinical trials and biomedical ethics committee of the Ethics Committee of the Second Affiliated Hospital of Jiaxing University and the Affiliated Changzhou No.2 People's Hospital of Nanjing Medical University. All individual participants voluntarily joined this study and provided written informed consent. All participating patients and institutions allowed us to access the data used in this study.

\section{Consent for publication}

The paper has obtained all participants' written informed consent for publishing their personal and clinical information.

\section{Competing interests}

The authors declare that conflicts of interests did not exist in the paper.

Received: 30 May 2020 Accepted: 4 October 2020

Published online: 09 October 2020

\section{References}

1. Nuki G. Osteoarthritis: a problem of joint failure. Z Rheumatol. 1999; 58(3):142-7.

2. Woolf AD, Pfleger B. Burden of major musculoskeletal conditions. Bull World Health Organ. 2003;81(9):646-56.

3. Peer MA, Lane J. The knee injury and osteoarthritis outcome score (KOOS): a review of its psychometric properties in people undergoing total knee arthroplasty. J Orthop Sports Phys Ther. 2013:43(1):20-8.

4. Sandell LJ. Etiology of osteoarthritis: genetics and synovial joint development. Nat Rev Rheumatol. 2012;8(2):77-89.

5. Rice SJ, Beier F, Young DA, Loughlin J. Interplay between genetics and epigenetics in osteoarthritis. Nat Rev Rheumatol. 2020;16(5):268-81.

6. Heinrich PC, Castell JV, Andus T. Interleukin-6 and the acute phase response Biochem J. 1990;265(3):621-36.

7. Garbers C, Heink S, Korn T, Rose-John S. Interleukin-6: designing specific therapeutics for a complex cytokine. Nat Rev Drug Discov. 2018;17(6): 395-412.

8. Kwan Tat S, Padrines M, Theoleyre S, Heymann D, Fortun Y. IL-6, RANKL, TNF-alpha/IL-1: interrelations in bone resorption pathophysiology. Cytokine Growth Factor Rev. 2004;15(1):49-60.

9. Goldring MB, Otero M, Tsuchimochi K, ljiri K, Li Y. Defining the roles of inflammatory and anabolic cytokines in cartilage metabolism. Ann Rheum Dis. 2008;67(Suppl 3):iii75-82

10. Sakao K, Takahashi KA, Arai Y, Saito M, Honjo K, Hiraoka N, et al. Osteoblasts derived from osteophytes produce interleukin-6, interleukin8 , and matrix metalloproteinase-13 in osteoarthritis. J Bone Miner Metab. 2009;27(4):412-23.
11. Singh M, Mastana S, Singh S, Juneja PK, Kaur T, Singh P. Promoter polymorphisms in IL-6 gene influence pro-inflammatory cytokines for the risk of osteoarthritis. Cytokine. 2020;127:154985.

12. Lv C, Xu X, Wang J, Zhang Z, Zhang D, Guo C, et al. Combined effect of cytokine gene polymorphisms on end-stage knee osteoarthritis from Chinese Han population. Rheumatol Int. 2011;32(11):3625-9.

13. Kapoor M, Martel-Pelletier J, Lajeunesse D, Pelletier JP, Fahmi H. Role of proinflammatory cytokines in the pathophysiology of osteoarthritis. Nat Rev Rheumatol. 2011;7(1):33-42.

14. Pozgan U, Caglic D, Rozman B, Nagase H, Turk V, Turk B. Expression and activity profiling of selected cysteine cathepsins and matrix metalloproteinases in synovial fluids from patients with rheumatoid arthritis and osteoarthritis. Biol Chem. 2010;391(5):571-9.

15. Cawston TE, Curry VA, Summers CA, Clark IM, Riley GP, Life PF, et al. The role of oncostatin $\mathrm{M}$ in animal and human connective tissue collagen turnover and its localization within the rheumatoid joint. Arthritis Rheum. 1998:41(10):1760-71.

16. Pelletier JP, Raynauld JP, Caron J, Mineau F, Abram F, Dorais M, et al. Decrease in serum level of matrix metalloproteinases is predictive of the disease-modifying effect of osteoarthritis drugs assessed by quantitative MR in patients with knee osteoarthritis. Ann Rheum Dis. 2010;69(12):2095-101.

17. Kugisaki H, Sonohata M, Komine M, Tsunoda K, Someya S, Honke H, et al. Serum concentrations of interleukin- 6 in patients following unilateral versus bilateral total knee arthroplasty. J Orthop Sci. 2009:14(4):437-42.

18. Alonzi T, Fattori E, Lazzaro D, Costa P, Probert L, Kollias G, et al. Interleukin 6 is required for the development of collagen-induced arthritis. J Exp Med. 1998;187(4):461-8.

\section{Publisher's Note}

Springer Nature remains neutral with regard to jurisdictional claims in published maps and institutional affiliations.
Ready to submit your research? Choose BMC and benefit from:

- fast, convenient online submission

- thorough peer review by experienced researchers in your field

- rapid publication on acceptance

- support for research data, including large and complex data types

- gold Open Access which fosters wider collaboration and increased citations

- maximum visibility for your research: over $100 \mathrm{M}$ website views per year

At $\mathrm{BMC}$, research is always in progress.

Learn more biomedcentral.com/submissions 